\title{
Citizen Typography and Political Brands in the 2016 US Presidential Election Campaign*
}

\author{
Thomas J Billard \\ Annenberg School for Communication \& Journalism, \\ University of Southern California \\ tbillard@usc.edu
}

March 15, 2018

\begin{abstract}
The 2016 presidential campaign between Hillary Clinton and Donald Trump saw citizen typography emerge in highly visible and highly impactful ways, particularly as the candidates made seemingly little attempt to maintain full control over their visual brand identities. But what does the surprising significance of typography in this recent campaign reveal about marketing and citizen participation in politics, about political brand management in a networked media environment, and about typography's role as a key pillar of branded political communication? This essay offers two key concepts: the networking of political brands and an emerging logic of participatory aesthetics - both of which point to a decentralisation of traditional 'brand management' in favour of affectively-driven political engagement through visual communications disseminated over communication networks.
\end{abstract}

Keywords typography, graphic design, political communication, presidential election, political branding

Cite as Billard, Thomas J. 2016. "Citizen Typography and Political Brands in the 2016 US Presidential Election Campaign." Marketing Theory 18 (3): 421-31. doi:10.1177/1470593118763982

\footnotetext{
* The author would like to thank Rachel Moran for extensive illuminating discussions in which the theoretical ideas presented here were developed. The author would also like to thank the three anonymous reviewers whose critiques and suggestions greatly improved the precision of the article's argument.
} 


\section{Introduction}

About two months before the election of Donald Trump to the presidency of the United States, I published an article on the importance of typography - and, by extension, graphic design in generalto the American political process (Billard, 2016). At the end of the article I postulated that, given the brand logics orienting contemporary politics (O'Cass, 2009; Scammell, 2007; Smith and French, 2009 ) and the prevalence of memetic activity in political discourse (Jenkins and Billard, 2018), ${ }^{1}$ citizen typography would emerge as increasingly relevant to the organisation of political campaigns. More specifically, I predicted the creation of typographic designs would allow citizen messages to weave seamlessly into the flow of political discourse from campaigns, decentring campaign staff's control over candidates' brand images and messaging.

The postulations were - at the time of writing - based on limited data and controversial theory: Such practices had only become prevalent during Barack Obama's 2008 campaign, and I critiqued these phenomena through the lens of Henry Jenkins's notion of participatory culture (e.g., Jenkins and Billard, 2018). But the 2016 presidential campaign between Trump and Hillary Clinton saw citizen typography emerge in much more visible and impactful ways than the article indicated, particularly as the candidates made seemingly little attempt to maintain full control over their visual brand identities. As Michael Bierut, designer of Clinton's $H$ logo, told Vox, the logic of contemporary (presidential) logo design is to allow easy manipulation of the logo system across diverse contexts and in diverse visual styles (Posner, 2015). Consequently, citizens could easily insert their own visual messages into the stream of campaign-originated communications. When coupled with citizens' other typographic designs (external to the logo system), this allowed for more fluid dynamics of discourse between the public and campaigns - and indeed, within the public, without any connection to campaigns. Thus, the purpose of this essay is to refine and expand upon my earlier propositions with the added data point of this recent election.

For clear evidence of the significance of citizen typography, we need not look far. Two parallel, but contrasting examples can be found in BF Tiny Hands (Figure 1) and Hillary Bold (Figure 2) two candidates, two typefaces, two different sentiments being expressed. The first, BF Tiny Hands, was developed by BuzzFeed using images of Trump's handwritten notes (King, 2016). The name is a politically astute joke, simultaneously mocking Trump's on-going obsession with his own hand size and, as an extension thereof, his masculinist politics. But in addition to giving the typeface an amusing name, BuzzFeed created a graphic parodying the common pangram used to test typefaces, 'The quick brown fox jumped over the lazy dog', by including some of the crude language Trump used to degrade women and his political opponents (Figure 1). Moreover, by making the typeface freely available to the public, they allowed citizens to create their own messages using Trump's writing, creating and distributing messages that looked as though they came from his own hand.

The second, Hillary Bold, was developed by freelance designer Rick Wolff and consists of an arrow-adorned alphabet inspired by Bierut's logo (Figure 2). In contrast to BF Tiny Hands, 'Hillvetica', as it was dubbed on Twitter, allowed citizens to whimsically express their support for, and identification with, Clinton. Even before Wolff released Hillary Bold as a TrueType font for download, the Washington Post released a macro on their website with which readers could generate messages set in his typeface. And as members of the social media sphere did so, sharing their designs online, the Clinton campaign took notice, with Clinton even tweeting her own message set in Hillary Bold (Figure 3). Whereas BF Tiny Hands enabled citizens to express disgust and mockery toward Trump, Hillary Bold enabled citizens to circulate messages of solidarity and, perhaps unexpectedly, participate in a typographically mediated dialogue with the Clinton campaign.

But what do these two typographic phenomena - along with various other examples throughout

\footnotetext{
${ }^{1}$ For a brief introduction to the controversy surrounding Jenkins's theorisations, see Hay and Couldry (2011).
} 


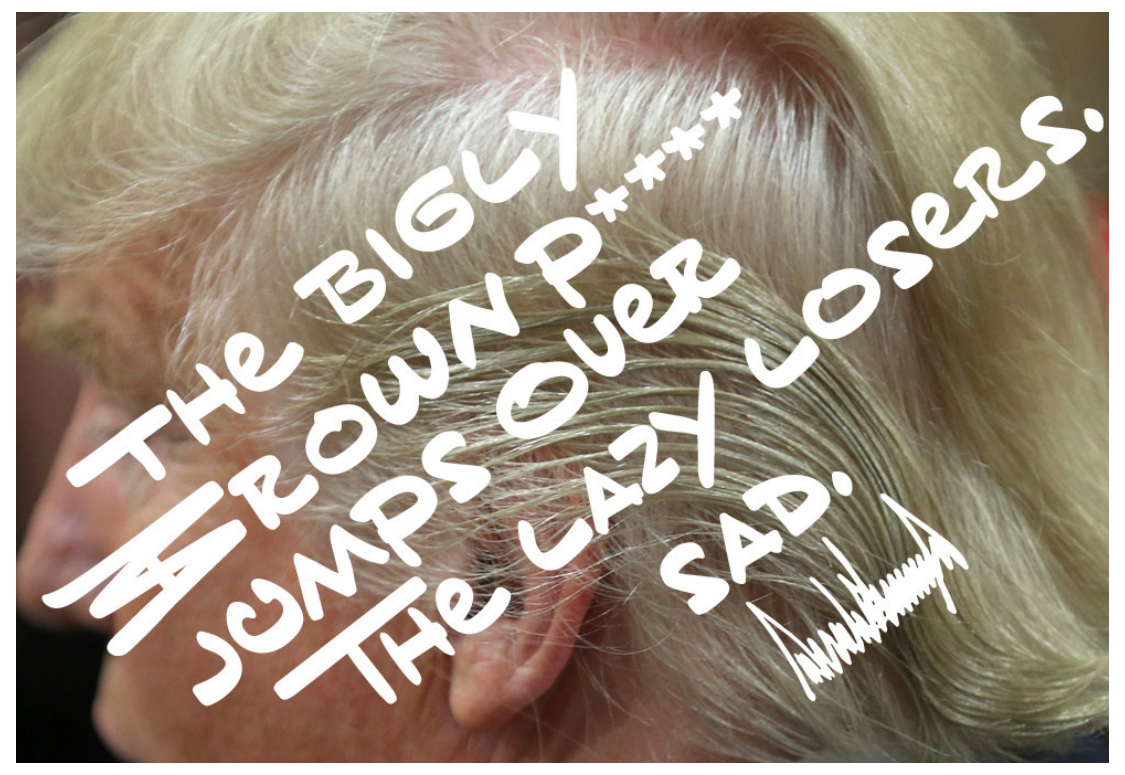

Figure 1: BF Tiny Hands by BuzzFeed.

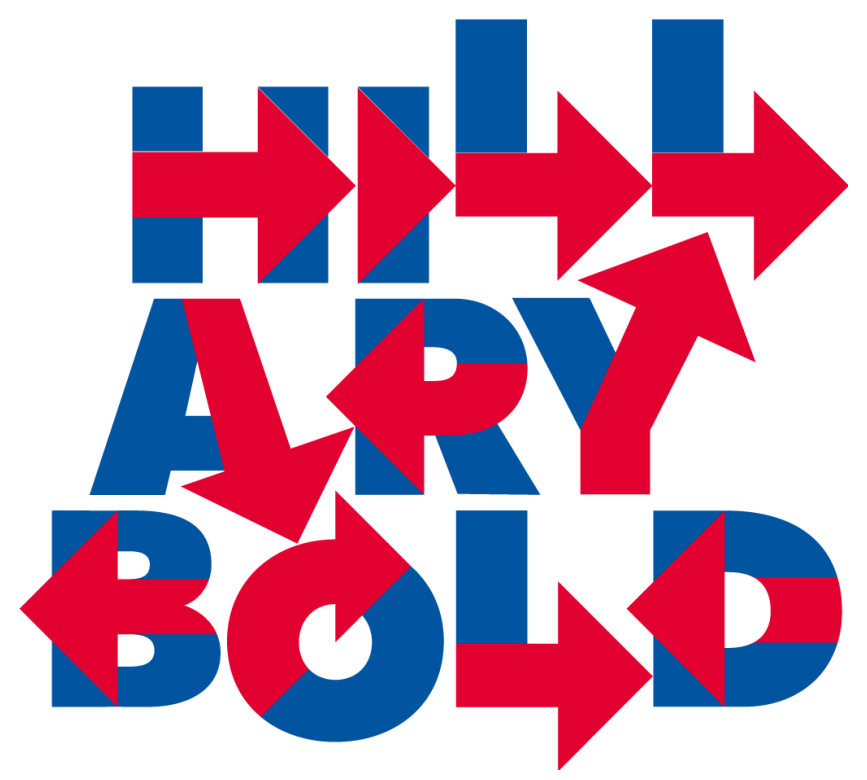

Figure 2: Hillary Bold by Rick Wolff. 


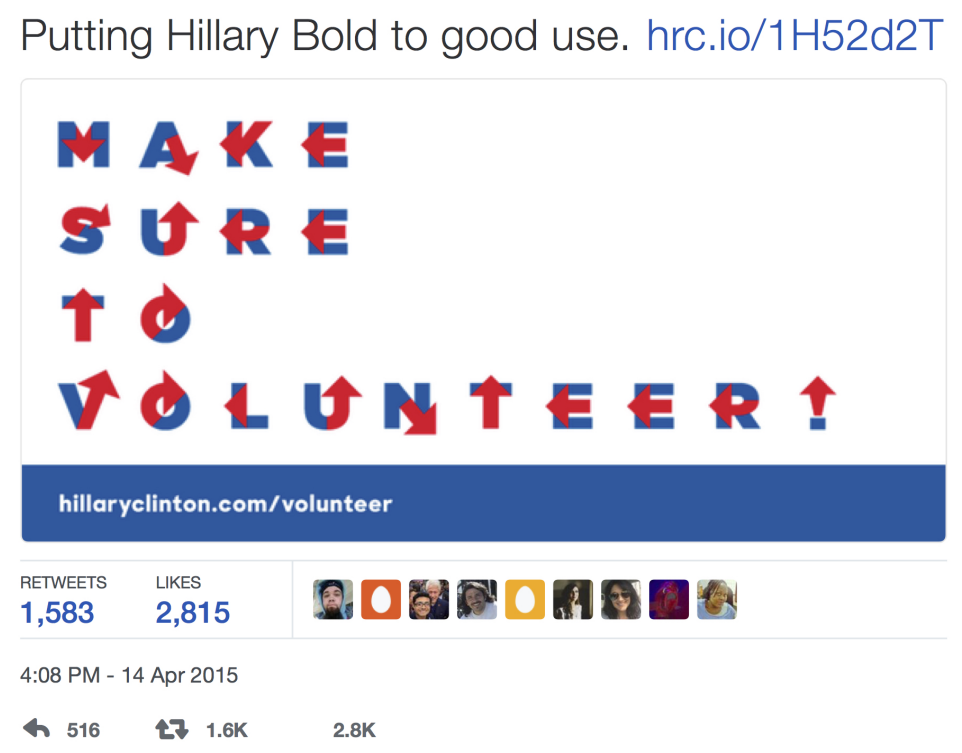

Figure 3: Clinton's tweet using Hillary Bold.

the 2016 presidential election campaign - reveal about marketing and citizen participation in politics, political brand management in a networked media environment, and typography's role as a key pillar of branded political communication? Two features deserve comment: the networking of political brands and an emerging logic of participatory aesthetics - both of which point to a decentralisation of traditional 'brand management' in favour of affectively-driven political engagement through visual communications disseminated over communication networks. This essay unpacks those ideas further.

\section{The Networking of Political Brands}

Contemporary politics is unquestionably organized through the logics of brand culture, both in the use of political messages to sell products (Banet-Weiser, 2012) and in the brand-focused marketing of political parties and candidates (Butler and Harris, 2009; Henneberg and Ormrod, 2013; O'Cass, 2009; Scammell, 2007; Smith and French, 2009). As Banet-Weiser (2012) noted, Obama's 2008 campaign signalled a shift in US politics toward pseudo-corporately branded candidates who develop sustained brands through networked communication technologies. And as Scammell has repeatedly shown (1995, 2003, 2007), electoral campaigns in both the US and UK have long employed traditional market research and brand management practices in the development of campaign messaging (see also Butler and Harris, 2009). Yet most analyses of candidate branding have only considered the role of citizens/consumers in the development and sustainment of political brands to a limited extent.

In contemporary brand culture, consumers play an active role in the creation of brand meaning as new forms of 'brand management' enable and encourage consumers to utilise the cultural resources of the brand in their own ways, for their own purposes (Brodie, Benson-Rea, and Medlin 2017; Schroeder, 2009). While this allows corporations to capitalise on the immaterial labour of 
consumers in generating and sustaining brand equity (Arvidsson, 2005), it also empowers consumers to transform the meaning of the brand through their own cultural productions. ${ }^{2}$ Moreover, these practices encourage the formation of what Muniz and O'Guinn (2001: 418) called 'brand communities', or 'social entities that reflect the situated embeddedness of brands in the day-to-day lives of consumers and the ways in which brands connect consumer to brand, and consumer to consumer.' Yet, as Arvidsson (2005: 248) observed, brands do not exist merely as nodes in the social networks of consumers (as Muniz and O'Guinn suggested), but as 'platforms for action'-sites for social exchange and interaction. Thus, contemporary brands exist as a space in which social networks form, which allows for the transformation of those social networks - and the communications and cultural productions within them - to necessarily transform the nature of the brand itself.

In politics, this active consumer role takes the form of citizen engagement through branded communications, and the social networks formed within the brand spaces of parties and candidates become engaged supporter bases (Butler and Harris 2009). For example, Smith and French (2009) pointed to the 2008 Obama campaign to illustrate how engaged brand communities (in this case, fostered by the campaign) translated into new networks of fundraisers, activists, voters, and allaround brand energisers. In the 2016 campaign, brand communities played a similar role, though in this context the networks largely formed independent of the campaigns (e.g., Pantsuit Nation, the 'Alt-Right', etc.). As Scammell (2003) remarked, while campaigns are often inclined to develop (and protect) centrally-controlled messages to ensure short-term advantage at the polls, there are greater gains to be made in energising existing memberships and fostering grassroots organising. As such, there is a strategic logic to focusing not on the dissemination of centrally-branded messages, but on the cultivation of communities around the political brand - specifically, building a brand space in which networks may form (Arvidsson, 2005) - as these networks constitute stronger, more enduring political ties than one-time mobilised voters.

However, the shift toward this networked branding further necessitates the decentralisation of brand control (Brodie, Benson-Rea, and Medlin, 2017; Moran and Billard, forthcoming). That is, political campaigns must move from developing what Pitt and colleagues (2006) called 'closed' brands to cultivating 'open' brands. Whereas closed brands are closely controlled by brand managers, open brands invite consumer participation in both the creation and subsequent transformation of brand meanings and messages (Pitt et al., 2006). Thus, when political campaigns engage in networked branding practices not only do they create a brand space but they also surrender control of that space, which in turn is co-constructed by supporters (or, less desirably, adversaries; cf. Cova and White, 2010) of the candidate/party. This consequently allows for the entry of citizen voices into campaigns' messaging, reshaping brand meanings.

I previously pointed to the Obama campaign as a key example, showing how supporters used the campaign's brand resources (the $O$ logo, the typeface Gotham, etc.) to signal their membership in his brand network and, through visual continuity with the campaign, contribute their messages to the stream of campaign-originated communications (Billard, 2016). In doing so, they transformed the Obama brand, attributing qualities to his brand through their communications that did not necessarily conform to the platform developed centrally by the campaign. In 2016, Clinton's supporters behaved similarly, parodying the $H$ logo and using the typeface Unity to generate political commentary that appeared as though it could have originated from the campaign itself (e.g., Figure 4). These supporters thereby transformed the Clinton brand - in positive ways - through the diffu-

\footnotetext{
${ }^{2}$ As Cova and White (2010: 256) wrote, 'Thanks to Web 2.0 technologies, consumers that belong to communities become significantly empowered in their relationships with companies that manage their favourite brands.' In politics, admittedly, ideas of citizen 'empowerment' through branding may seem only shallowly democratic. It is thus important to note the 'empowerment' to which I refer is a communicative empowerment (Castells, 2013), not empowerment in terms of institutional political power, which remains constrained by the practical limits of governmental and electoral systems.
} 
sion of original content across the brand network. Alternatively, opponents of the Trump campaign parodied his logo in ways that mocked the future president - thus transforming his brand in negative ways - ultimately driving the campaign to release a new logo that was harder to manipulate (Jenkins and Billard, 2018).

As such, the networking of political brands in the 2016 election parallels in some ways what marketing scholars have called 'integrative branding' (Brodie, Benson-Rea, and Medlin, 2017) and 'counter-' and 'alter-branding' (Cova and White, 2010) practices. Regarding the latter, Cova and White (2010: 256-57) observed that the Internet has empowered consumers to co-produce brand value in ways that are 'not always exactly what the brand strategists had in mind', which may alternately present brand managers with novel opportunities or novel threats. For instance, 'counterbrands' present novel threats as frustrated members of the brand community produce spin-off brands in what Cova and White (2010: 264) characterised as a 'secessionist community.' Brodie, BensonRea, and Medlin's (2017) concept of 'integrative branding' offers a similar perceptive. As they argued, branding activities are 'undertaken in a network, where specific actors build and adjust identity and meaning' (Brodie, Benson-Rea, and Medlin, 2017: 185). As a necessary consequence of this networked nature, however, the activities of the various actors within the network may run 'counter to the interests of other actors' (Brodie, Benson-Rea, and Medlin, 2017: 185), resulting either in a negotiated or a disintegrated brand meaning. Whereas the Clinton campaign successfully facilitated the negotiation of brand meaning, the Trump campaign failed to prevent the disintegration of brand meaning and thus intervened to recentralise control over the brand by revising its visual brand resources. From this perspective, citizens' capacity to transform the meaning of a candidate's political brand can result in either (1) a successfully integrated brand co-constructed by both campaign staff and citizens or (2) a disintegrated brand over which campaign staff lose control, depending on the composition and communicative activities of citizen-actors within the candidate's brand network.

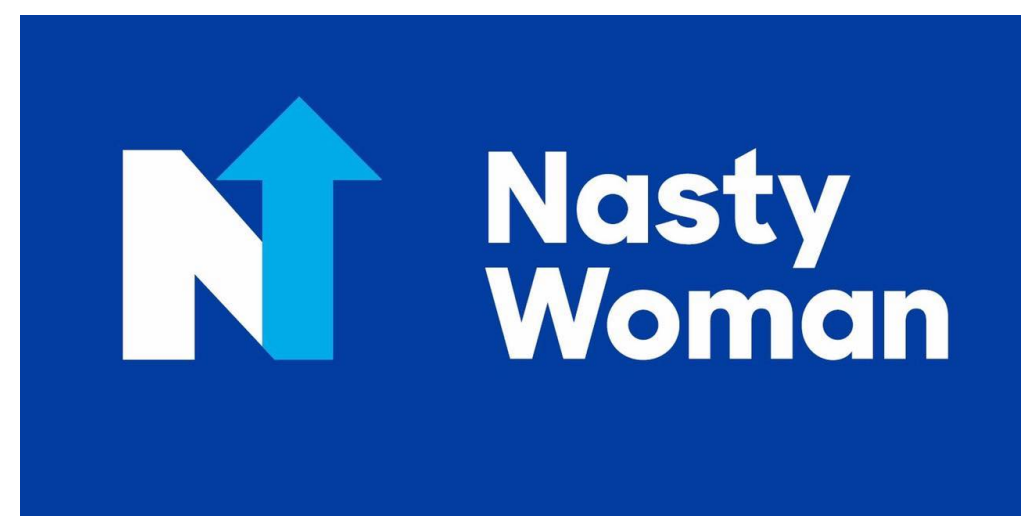

Figure 4: Nasty Woman logo.

Significantly, this ability of brand networks to alter candidate brands is made possible by what I have called the 'elasticity' of campaigns' design materials (Billard, 2016), which allows technologically-empowered citizens to create their own (aesthetically) authentic designs with little effort. However, the choice campaigns make to produce brand designs intended to be manipulated in this way - which is part of the effort to generate a networkable brand space-constitutes an emerging logic within brand-driven campaigns of what I'm terming participatory aesthetics. 


\section{The Logic of Participatory Aesthetics}

In their work on brand communities, Muniz and O'Guinn (2001) identified several conditions under which communities are likely to form: the brand has a strong image; has a long, rich history; has strong competitors; and is consumed publically. Each can certainly be true of political candidates and parties. In an era of networked brands, however, another condition must be added: networks are likely to form in brand spaces open to participation and transformation. Particularly in political contexts, the formation of brand networks depends on the openness of the political brand. As Bennett and Segerberg (2012) suggested in their conceptualisation of 'connective action', networks of political action are connected through the co-production of messages that express personalised sentiments. Thus, to foster connective action within the network of a political brand, the exchange of co-producible and personalisable messages must be made easy. One significant way for campaigns to achieve this is through the design features of their visual brand materials.

In the words of Schroeder (2005: 1292), 'Brands are inherently visual; brand logos, ? brand identity, and brand marketing campaigns each draw upon visual materials to create distinctive brand images.' Brands are also inherently ideological to the extent that branding - with its 'socially constructed signs, marks and meanings' - 'is the principal symbolic practice of the marketing imagination' (O'Reilly, 2006: 268). In the realm of politics, therefore, visual brand resources become markers of political meaning, and citizen participation in their generation and transformation allows citizen voices to shape the ideological messages of a candidate's brand (Billard, 2016). Thus, by designing visual brand resources in ways that permit citizen transformation, campaigns foster such connective action.
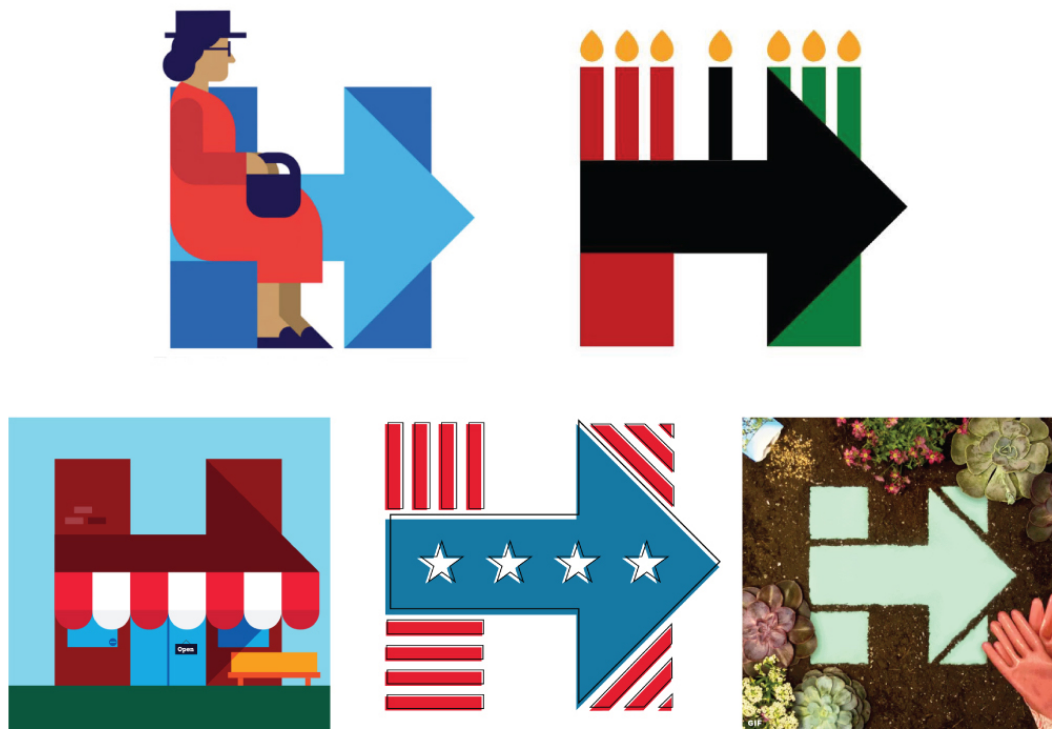

Figure 5: $H$ logo variations.

For instance, the design of Obama's brand materials achieved high levels of spreadability because they were specifically developed to permit the creation of new designs (Billard, 2016). Moreover, the technological ease of typographic manipulation meant almost anyone could participate in the brand network through such creations. The same was true of Clinton's 2016 campaign. Indeed, Michael Bierut designed Clinton's logo with the explicit intention it could be easily transformed 

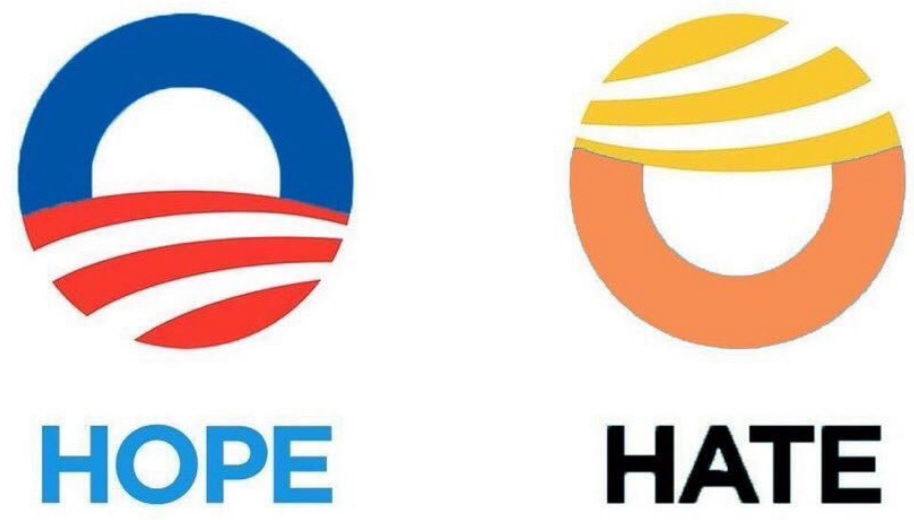

HATE

Figure 6: Obama contrasted with Trump.

and adapted - whether by campaign staff or the public. As he explained, the 'simple forms' of the arrow-adorned $H$ were designed not merely to contain the standard red and blue (or, later, blue and white), but any variety of colours, shapes, images, etc. to express new messages (Posner, 2015; e.g., Figure 5). This choice, dictated by the desire to invite citizen contributions to the campaign's communications, clearly reflects the logic of participatory aesthetics.

This is not to say participatory aesthetics are necessarily positive in their valence (cf. Cova and White, 2010). Whereas use of the Obama and Clinton campaigns' visual brand resources were largely (though not exclusively) driven by support for the candidates, use of Trump's resources was overwhelmingly driven by resistance. For example, citizen-generated parodies of the original Trump/Pence logo mocked the candidates' homophobic policies with designs that rendered the logo's interlocking $\mathrm{T}$ and $\mathrm{P}$ sexually suggestive (Jenkins and Billard, 2018). Thus, the logic of participatory aesthetics dictates that by placing a central emphasis on adaptive brand designs - particularly in a digital age - (political) brands invite the participation of citizens/consumers, even when they do not intend for participation to occur. And indeed, after ridiculous redesigns of the original Trump/Pence logo diffused over social media, the campaign issued a non-adaptive redesign - a simple wordmark set in a plain sans-serif typeface.

Yet, because of the adaptability of his opponents' brand materials, resistance to Trump's politics could still be expressed through supportive affiliation with those opponents. For example, after Trump called Clinton a 'nasty woman' in the final presidential debate, citizens generated redesigns of Clinton's brand materials, reclaiming the insult as a central element of the Clinton brand (Figure 4). Likewise, citizens used the famed Obama logo to draw contrast between Obama's campaign promise of hope and Trump's far-right conservatism (Figure 6). While this former case falls clearly within the model of networked political branding I have outlined, as the Clinton campaign's brand network co-opted a counter-message to negotiate a positive brand meaning, the latter represents a 
productive disruption to it: in a manner analogous to 'counter-branding' (Cova and White, 2010), citizens employed brand resources from outside the campaign to attack the equity of the parent brand and transform its public meaning.

What these examples further make salient is the centrality of affect to citizen designs. That is, as Papacharissi (2015: 3) suggested, citizens express 'rationally focused expressions of ideological beliefs' through designs imbued with affect rather than reason. As such, participatory aesthetics must be understood as constituting the ways in which brand- and design-centred campaigns invite citizens to engage in politics by expressing affective orientations toward politics and thereby form networks of political action in connective, rather collective ways. And yet, because of the networked nature of political brands, these affective engagements may still be transformative and - as Preece (2015) has shown in her research on celebrity branding - authentic.

\section{Conclusion}

At the end of his essay on 'the dreary art of presidential elections', Heller (2004) remarked, '[b]uttons, bumper stickers, and posters are not going to swing votes - they are but reminders and signs of affiliation.' Indeed, he is right: the designed elements of campaigns alone will not determine the outcome of the election. Nowhere is that clearer than in the 2016 election, in which a candidate who-among other criteria- bested her opponent in branding and design nonetheless lost. But by understanding the significance of typography and graphic design to the emerging practices of networked branding and the increasingly dominant logic of participatory aesthetics, we can better theorise the ways in which visual communications exchanged over communication networks contribute to the organisation of contemporary politics.

This of course raises important normative questions about democracy and citizenship; as Henneberg, Scammell, and O'Shaughnessy (2009: 165) wrote, marketing perspectives on politics are often critiqued for 'devaluing democratic processes.' Yet as many scholars have noted (e.g., O'Cass, 2009; Smith and French, 2009), these perspectives are theoretically productive because (for better or worse) they both inform the practice of politics by professionals and structure the participation of citizens in electoral politics. While some scholars have argued different political marketing approaches suit different models of democracy - with the types of relational branding described in this article fitting a more deliberative model of democracy (Henneberg, Scammell, and O'Shaughnessy, 2009) - I do not pronounce any normative (or moral) evaluations of the practices I have analysed. Rather, I recognize that, where it concerns elections, political parties and candidates 'are brands because they act as brands to consumers' (Smith and French, 2009: 211) and because parties and candidates structure their activities like commercial marketers and brand managers (O'Cass, 2009). Thus, my aim is to theorise the dynamics of political branding in actually existing democracy and to explicate how networked communication technologies have altered the distribution of communicative power in ways that empower citizens to more actively participate in the activities of brand co-construction and transformation.

While this article presents two key theoretical constructs to this end-the networking of political brands and logic of participatory aesthetics - several important questions remain open for future investigation. The first set of questions centre around the fact that, despite less successfully cultivating a brand network and limiting citizen participation in co-productive design practices, Donald Trump still won. What does his victory imply about the efficacy of political branding and the significance of participation in campaign branding practices? Further questions centre around participation itself: Which citizens are most likely to engage in this type of aesthetic participation, and what might potential differences between this participating subset and the general population mean for how (un)representatively a candidate's brand is transformed? What barriers - in both material 
resources and cultural capital - exist to such participation, and how does that limit the scope of these branding practices? Finally, important work must be done to identify the boundaries, if they exist, between citizen engagement and consumer engagement; where are these practices indicative of the former, and where of the latter? Do these practices fuel engagement in the political process or only in political consumption? Such questions have profound implications both for the study of political marketing and for democratic ideals. 


\section{References}

Arvidsson, A. (2005) 'Brands: A Critical Perspective', Journal of Consumer Culture 5(2): 235-58. Banet-Weiser, S. (2012) Authentic ${ }^{T M}$ : The Politics of Ambivalence in a Brand Culture. New York: New York University Press.

Bennett, W.L. and Segerberg, A. (2012) 'The Logic of Connective Action', Information, Communication 85 Society 15(5): 739-68.

Billard, T.J. (2016) 'Fonts of Potential: Areas for Typographic Research in Political Communication', International Journal of Communication 10: 4570-92.

Brodie, R.J., Benson-Rea, M., and Medlin, C.J. (2017) 'Branding as a Dynamic Capability', Marketing Theory 17(2): 183-99.

Butler, P. and Harris, P. (2009) 'Considerations on the Evolution of Political Marketing Theory', Marketing Theory 9(2): 149-64.

Castells, M. (2013) Communication Power. Oxford: Oxford University Press.

Cova, B. and White, T. (2010) 'Counter-brand and Alter-brand Communities', Journal of Marketing Management 36(3-4): 256-70.

Hay, J. and Couldry, N. (2011) 'Rethinking Convergence/Culture', Cultural Studies 25(4-5): 473-86.

Heller, S. (2004) 'The Dreary Art of Presidential Elections,' AIGA. http://www.aiga.org/the-drearyart-of-presidential-elections/

Henneberg, S.C. and Ormrod, R.P. (2013) 'The Triadic Interaction Model of Political Marketing Exchange', Marketing Theory 13(1): 87-103.

Henneberg, S.C., Scammell, M., and O'Shaughnessy, N.J. (2009) 'Political Marketing Management and Theories of Democracy', Marketing Theory 9(2): 165-88.

Jenkins, H. and Billard, T.J. (2018) 'Participatory Politics', in E. Navas, O. Gallagher, and x. burrough (eds) Keywords in Remix Studies, pp. 230-45. New York: Routledge.

King, B. (2016) 'Tiny Hand will be your new Comic Sans', BuzzFeed. https://www.buzzfeed.com/benking/tiny-hand-will-be-your-new-comic-sans

Moran, R.E. and Billard, T.J. (forthcoming) 'Imagining Resistance to Trump through the Networked Branding of the National Park Service', In H. Jenkins, S. Shresthova, and G. Peters-Lazaro (eds) Popular Culture and the Civic Imagination: A Casebook. New York: New York University Press.

Muniz, A.M. and O'Guinn, T.C. (2001) 'Brand Community', Journal of Consumer Research 27(4): $412-32$.

O'Cass, A. (2009) 'A Resource-Based View of the Political Party and Value Creation for the VoterCitizen', Marketing Theory 9(2): 189-208.

O'Reilly, D. (2006) 'Branding Ideology', Marketing Theory 6(2): 263-71.

Papacharissi, Z. (2015) Affective Publics. Oxford: Oxford University Press.

Pitt, L.F., Watson, R.T., Berthon, P., Wynn, D., and Zinkhan, G. (2006) 'Corporate Brands from an Open Source Perspective', Journal of the Academy of Marketing Science 34(2): 115-27.

Posner, J. (2015) 'What Makes a Truly Great Logo', Vox. http://www.vox.com/2015/12/28/10673530/logo-design-bierut

Preece, C. (2015) 'The Authentic Celebrity Brand', Journal of Marketing Management 31(5-6): $616-45$.

Scammell, M. (1995) Designer Politics. New York: St. Martin's Press.

Scammell, M. (2003) 'Citizen Consumers: Towards a New Marketing of Politics?', In J. Corner and D. Pels (eds) Media and the Restyling of Politics, pp. 117-36. London: Sage.

Scammell, M. (2007) 'Political Brands and Consumer Citizens: The Rebranding of Tony Blair', Annals of the American Academy of Political and Social Science 611: 176-92.

Schroeder, J.E. (2005) 'The Artist and the Brand', European Journal of Marketing 39(11/12): 1291305. 
Schroeder, J.E. (2009) 'The Cultural Codes of Branding', Marketing Theory 9(1): 123-26.

Smith, G.S. and French, A. (2009) 'The Political Brand: A Consumer Perspective', Marketing Theory $9(2): 209-26$. 